\title{
Who was William Hyde Wollaston?
}

A review of Pure Intelligence: The Life of William Hyde Wollaston by Melvyn C. Usselman. Chicago: University of Chicago Press. 424pp. ISBN 9780226245737 and 5874 (e-book). Published 5 June 2015.

In 1989 the distinguished historian of science Steven Shapin published an essay entitled “Who was Robert Hooke?” Shapin's essay addressed a fundamental question, one with which historians of science continue to wrestle: what are the "philosophical consequences of [paying] attention to the social identity of practitioners" (p. 282)? For Shapin, analyzing the life as well as the work of Robert Hooke (1635-1703) in seventeenth century London had the power to reveal what it meant to be an experimental philosopher - a term encapsulating the ambiguity at the heart of Hooke's problematic social status.

Neither technician nor gentleman, Hooke struggled to establish and sustain his social position and scientific standing as he moved between the public and private spheres of his life. And it was only by understanding this struggle, Shapin argued, that we might properly appreciate both Hooke's resentment when social superiors doubted his experimental results, and the freedom with which they did so (pp. 282-5). Hooke may have been "the greatest Mechanick this Day in the World" (p. 253). But this did not make him a philosopher to his contemporaries. According to Shapin, by confining Hooke to the disembodied category of scientist (or natural philosopher: Shapin's point was not a merely semantic one) we lose all possibility of comprehending who Hooke was - and, as a result, the true nature of his accomplishments. ${ }^{1}$

In this essay review, Melvyn Usselman's recently published biography of William Hyde Wollaston (1766-1828) provides a welcome opportunity to revisit the role of biography in the history of science. Among a plethora of recent biographies, both scholarly and more

${ }^{1}$ Hooke, of course, was the subject of much biographical writing before and after Shapin's essay, including Lisa Jardine's (2003) book-length biography, The Curious Life of Robert Hooke. 
popular, Usselman's study of Wollaston stands out as particularly appropriate for this purpose. Although Wollaston lived almost two centuries after Hooke, his was also an ambiguous life. That life, moreover, was lived during a period of similar upheaval in science: where Hooke and his contemporaries were prime movers in the Scientific Revolution, Wollaston's lifetime paralleled the period in which the scientist became a professional. Wollaston's biography therefore offers a richness of historical possibility against which to test what we think a good biography might and should do.

This is a timely question. Shapin's essay on Hooke contributed to an existing debate concerning the proper (or possible) role of biography in the history of science. ${ }^{2}$ That debate has been revisited on a number of occasions during the intervening decades, and it continues to be lively. A Focus section of the journal Isis addressed exactly this issue in 2006. And, while drafting this essay, I was also preparing to contribute to a roundtable discussion of scientific biography at the History of Science Society's Annual Meeting in San Francisco in November 2015. Today's historians of science are as concerned as they have ever been with the possibilities and problems of biography.

Mary Jo Nye, award-winning biographer of the chemist Linus Pauling and the physicist Patrick Blackett, argued in her contribution to the 2006 Isis Focus section that: "While historians of science often use biography as a vehicle to analyze scientific processes and scientific culture, the most compelling scientific biographies are ones that portray the ambitions, passions, disappointments, and moral choices that characterize a scientist's life" (Nye 2006, 322). Nye concluded (p. 329) that it was possible for biographies to be both "rich in science" and successful in reaching a readership beyond professional historians of science. It is no surprise, but is nevertheless worth noting, that her analysis revealed the scientist rather than his science as the engaging core of a successful biography.

Nye reached this conclusion in large part by considering biography as a means by which historians of science might engage an audience beyond their immediate colleagues. But her underlying problematic is just as relevant in the purely academic, disciplinary context. Where Shapin was arguing that scientific accomplishment could only be adequately

${ }^{2}$ For a contemporary discussion of the early phase of this debate, see Harman 1979. 
explained by paying attention to the personal situation and character of the scientist, Nye's analysis probed the opposite extreme. If we accept that the scientist's personal situation and character - rather than their science - lie at the heart of a successful biography, then some important concerns arise. How effective can biography be in explaining its subject's scientific work, except insofar as this is performed in the role of administrator, manager, and fund-raiser? To what extent can, and should, scientific biographies include, analyze, and even focus on their subject's science? These are far from the only matters of relevance to would-be scientific biographers. In the aftermath of a series of disciplinary shifts that have seen scientific biography fall out of favor with historians of science, only to re-emerge as a popular mode of analysis, it is also pertinent to ask what biographical studies might and should add to our understanding of science and its history.

Usselman's biography of Wollaston is an especially relevant case study in relation to these questions. Usselman, whose sudden death in April 2015 shocked and saddened his many friends and admirers in the field of history of chemistry, was a distinguished academic chemist with a scholar's passion for the history of his science, and for the remarkable career of William Hyde Wollaston in particular. For Usselman, Wollaston's fascination lay squarely in his science. This was where Usselman began, with a series of historical reconstructions of Wollaston's work spanning more than 40 years. And it was also where he ended, with a biography that places Wollaston's scientific and technical accomplishments front and center: Usselman's book is simultaneously a life's work and the study of a life in science.

Published by the University of Chicago Press in collaboration with the Chemical Heritage Foundation as part of the Synthesis series, Pure Intelligence is far from being the kind of dry, dusty biography only a fellow aficionado - of chemistry and its history, if not of Wollaston as an individual - might appreciate. On the contrary, it is a well-written and engaging account that juxtaposes a remarkable scientific career with the life of an intensely private man. These qualities confirm Usselman's Pure Intelligence as an appropriate test case for the concerns raised above. Transposed into more specific form, these take shape in the following questions. First, what does the lived experience of William Hyde Wollaston 
revealed by Usselman contribute to our historical understanding of Wollaston's science, the science of Wollaston's time, and those times more generally? Answering these questions is the ultimate goal of this essay but let me continue by introducing Usselman's Wollaston.

\section{The William Hyde Wollaston of Melvyn C. Usselman}

William Hyde Wollaston was born in London, England in 1766 and died in the rural county of Dorset some sixty-two years later. The intervening period had seen Wollaston qualify and practice as a physician only to abandon this career; enter a commercial partnership with the mercurial entrepreneur Smithson Tennant from which Wollaston subsequently retreated; first seek and later refuse a professorial appointment in his alma mater Cambridge University; and render significant service to the British Government through various committees of London's Royal Society, though he never became President of that illustrious institution. Through it all, Wollaston was an inveterate experimenter of considerable skill and broad scientific interests. He was also something almost more unusual: Wollaston made a living as a scientist in the early nineteenth century.

Though born into a relatively affluent family, Wollaston was not immediately in possession of an independent income. In deciding to leave medical practice in 1800, Wollaston gave up his most obvious route to financial security. His big commercial breakthrough, as well as his most widely known claim to fame, came in 1801, when Wollaston at last found a method of preparing malleable platinum. This valuable metal had, until that point, resisted all attempts to produce it in workable, pure form. Wollaston had solved a difficult technical problem, and he went on to make a considerable fortune from this discovery. He had also taken an important step towards establishing his reputation as a practical natural philosopher. A description of Wollaston's day of discovery (Wednesday, April 15) therefore makes a fitting starting point for Usselman's biography. ${ }^{3}$

That Wollaston has remained relatively little known can partly be attributed to the failure of his earliest biographer and friend Henry Warburton to complete the job in 1829.

\footnotetext{
${ }^{3}$ It is also an act of unspoken (perhaps unintended?) homage to Shapin's account of a day in the life of his subject, Robert Hooke.
} 
Warburton's loss, however, was Usselman's gain, leaving the field clear for Usselman to bring Wollaston to the attention of twenty-first century readers. Warburton's notes, of course, became a valuable source for Usselman, as did the more personal biographical recollections of Julia Hankey and Henry Hasted, each of whom joined the select circle of Wollaston's friends at different stages in his life. Sources form the core of any historical project, and Usselman's was made possible by the survival of a significant archive of Wollaston's correspondence and accounts, as well as by the mid-twentieth century rediscovery of many of Wollaston's laboratory notebooks. It is also greatly to his credit that Usselman in turn produced reader's guides for several collections of Wollaston's papers, thereby rendering them vastly more accessible to future scholars.

A key goal for Usselman was to restore Wollaston's reputation as “one of England's greatest scientists," on a par with better-remembered scientific giants of the early nineteenth century including Humphry Davy, Thomas Young, and Michael Faraday (7). That goal highlights another essential question for the prospective biographer: whom we are to remember, and why? The legendary experimenter Michael Faraday, for example, was born poor and was enabled to pursue a life in science by the patronage of Davy and the considerable resources of London's Royal Institution. It is easy to comprehend why a job at the Royal Institution was an attractive option to the young Faraday. And it is equally understandable that the combination of rags-to-riches storyline and foundational discoveries in chemistry, electricity, and magnetism has made Faraday an attractive subject for biographers beginning with John Tyndall in 1868.

Wollaston, by contrast, was the younger son of a wealthy and successful family of significant social standing. This makes Wollaston's story simultaneously much harder to provide with a compelling narrative arc and all the more fascinating. Wollaston's expensive Cambridge education prepared him for medical practice, a sure enough way of earning a good living until inheritance could make him independently wealthy. Once Wollaston committed himself to a life in science, Pure Intelligence (somewhat ironically) reveals him to have possessed outstanding manipulative and experimental skill, perhaps even approaching a par with Faraday's. 
Usselman makes no explicit comparison with Faraday, despite the opportunity this might have offered to restore Wollaston to a deserved position among the greats of early nineteenth century chemistry. He does, however, recount one famous episode that directly connects Wollaston and Faraday: what Usselman terms "the Faraday incident" (p. 312), and which took place during the early 1820s, when both Wollaston and Faraday engaged in experiments concerning the new phenomenon of electromagnetism.

It was Faraday whose experiments established the nature of electromagnetic rotation. In publishing his results, however, Faraday initially made no mention of Wollaston's earlier and somewhat inconclusive experimental work, an omission that in certain quarters called Faraday's scientific integrity into question. Usselman's brief account of this controversy does a good job of resuscitating Wollaston's behavior towards Faraday: Wollaston was "standoffish" at first (p. 315) but ultimately helped Faraday overcome this misunderstanding and aided his petition to become a Fellow of the Royal Society. But because Usselman chose not to examine the relationship between Wollaston's work and Faraday's in detail, his account of these well-known events does not advance our understanding of the relative merits of Faraday and Wollaston as experimental scientists. ${ }^{4}$

Why, then, is Wollaston worthy of a biography? A good part of the reason, it seems to me, is to be found in answering another series of questions. Why, exactly, did Wollaston give up the stability and status of life as a country physician to pursue a considerably more precarious existence as a scientific entrepreneur in London? And how, having made this move, did Wollaston - a retiring character who, on the face of it, was an unlikely candidate for entrepreneurial success - build a career?

The answer to the first of these questions, according to Usselman, is largely negative: Wollaston simply did not like being a doctor. The final straw came in 1800, when

\footnotetext{
4 The classic study addressing this question was David Gooding's (1985) essay "In Nature's School." Gooding used Faraday's laboratory notebooks to argue that although Faraday's work ultimately "ruled out Wollaston's hypothesis" (p. 119) his experimental approach was not motivated by a desire to test Wollaston's theory of rotating currents (pp. 115-16). It would have been most interesting to see Usselman's evaluation of this claim but Gooding's essay is not cited.
} 
Wollaston lost out to Charles Nevinson in the election for an appointment at St George's Hospital in London. Wollaston responded by abandoning medicine for science. Beyond this, Usselman remains tentative on this extraordinarily significant point. As he also shows, however, Wollaston by this time had already begun a series of scientific investigations, including the chemical analysis of spring and well waters. Even more important, he had struck up a friendship while a student in Cambridge with the "[e]ccentric Smithson Tennant" (p. 21).

Usselman clearly recognizes that the relationship between Wollaston and Tennant, though ultimately unsatisfactory, was potentially formative (p. 23). But, although he has studied Tennant's career in some detail, Usselman leaves the impact on Wollaston of meeting, getting to know, and working with this older, more experienced, better-traveled, and decidedly more flamboyant chemist largely unexplored. The question of what Wollaston learned from Tennant is particularly salient. Usselman describes Tennant's acquaintance with the French chemists Claude Louis Berthollet and Guyton de Morveau, and his early conversion to Antoine Lavoisier's new chemistry of the elements. Similarly, we read that Tennant learned the art of mineral analysis using the blowpipe from Swedish master analyst Johan Gottlieb Gahn. These observations situate Tennant at the leading edge of English chemistry in both theory and practice, and they gesture invitingly towards a possible mechanism by which Wollaston acquired his chemical knowledge and remarkable manipulative prowess. In the event, and much to my regret, Usselman chose not to pursue this suggestive connection, even though he provides no alternative account of how Wollaston became a skilled chemist.

However he accomplished the transition, becoming a natural philosopher in early nineteenth-century London transformed Wollaston's situation. Though he retained his fellowship at Caius College, Cambridge, Wollaston soon stopped attending meetings of the Royal College of Physicians. Instead Wollaston devoted his time to meetings of the Royal Society, where he had been elected a Fellow in 1793 (pp. 60-61, 28). He was also developing a connection with Humphry Davy, and experimenting with electricity and laughing gas at London's Royal Institution (p. 57, 63). Right from the start, well before he 
could support himself through science, Wollaston sat squarely at the heart of London's scientific elite.

Pure Intelligence reliably chronicles Wollaston's personal and institutional connections but these never coalesce to form a fully-fledged context for Wollaston and his work. This is due in part to some marked omissions from the cited secondary literature. Jan Golinski's classic (1999) study of the Royal Institution Science as Public Culture, for example, is noticeably absent. Usselman's published essays have clearly superseded Golinski's brief accounts of several episodes involving Wollaston that took place at the Royal Institution. Nevertheless, Golinski's book would surely have proved useful in developing a clearer overall vision of Wollaston's institutional setting and scientific milieu - and it would certainly have been a helpful citation for anyone drawn into the history of early nineteenth century London chemistry by Usselman's book. ${ }^{5}$

Several other factors contribute to the book's somewhat limited sense of place. Some of these are inescapable. Wollaston did much of his experimental work in laboratories at his various London homes. The discovery of malleable platinum, for example, took place in the back room of 18 Cecil Street, where Wollaston lived for almost exactly four years beginning in September 1797 (p. 39). From here, Wollaston moved to a larger house at 14 Buckingham Street near Regent's Park. Since Wollaston continued to live at this address until 1825, the Buckingham Street house was the site of much of his scientific work. Unfortunately, however, World War II bombing destroyed the house, along with any historical evidence it might still have provided (p. 59).

The larger problem in this regard, however, is organizational. By choosing to form chapters around distinct facets of Wollaston's scientific work, Usselman's narrative makes repeated geographical leaps that are disconcerting to any reader who attempts to track where work was being done. In describing Wollaston's early experiments on galvanism (current electricity), for example, Usselman carefully explains that some of this work was

${ }^{5}$ Golinski's Science as Public Culture is far from the only such omission. In addition to the absence of a citation to Gooding 1985 (note 4 above) I was also surprised to find no citation to Myles Jackson's (2000) study of Fraunhofer and the early nineteenth-century development of optics, Spectrum of Belief. 
done during a tour of the English Lake District. But the fact that Wollaston did many of these experiments at the Royal Institution appears only as an aside some pages into the narrative.

This latter, of course, is an extremely illuminating point. We know from Golinski's study that the resources of the Royal Institution were essential in enabling Davy to construct a Voltaic pile of unprecedented power with which to out-experiment European chemists. That Wollaston demonstrated his homemade miniaturized electrical machine in that same location is powerful grist to Usselman's mill: Wollaston's contemporaries were in no doubt about the significance of his work (p. 57). All the more reason, then, that we should understand its setting and context.

Wollaston's connections to Davy at the Royal Institution, and to the Royal Society, reflect his growing reputation as a natural philosopher. Wollaston, meanwhile, was also building commercial scientific capital, in the form of the new metals platinum, palladium, and rhodium (Chapters 4, 5 \& 7), through the development of new optical devices including the camera lucida (Chapter 6), and by producing and selling organic chemicals (Chapter 8).

Platinum made Wollaston financially secure, and it remains the accomplishment for which Wollaston is best known. For me, however, Wollaston's excursion into organic chemistry was one of the most fascinating and illuminating chapters in Pure Intelligence. This is partly for reasons relating to my particular interests in the history of nineteenth century chemistry. Usselman in this chapter uses Wollaston's laboratory notebooks to provide insight into his experimental practice, and to highlight Wollaston's under-acknowledged contributions to the practical development of chemical atomism through his work on integral combining proportions (pp. 212-19). In addition, and of more general significance, this chapter reinforces the sheer breadth of Wollaston's expertise, and his absolute determination to make science pay. As a result, Wollaston's work in the field of commercial organic chemicals sheds considerable light on the second question raised above: how did Wollaston become a successful entrepreneurial scientist? 
One factor in Wollaston's success is that he did not work alone. His assistant John Dowse performed much of Wollaston's routine laboratory work, including the especially "laborious and time-consuming processes" (p. 196) involved in doing organic chemistry. Usselman here draws an interesting comparison between what Wollaston paid Dowse and what Faraday received when he became Davy's assistant at the Royal Institution: Dowse's wages in 1805 matched what Faraday would receive as Davy's assistant almost a decade later. This provides Usselman with tangible evidence that Wollaston valued Dowse's contribution to his growing business (p. 196). It also highlights access to reliable, skilled labor in the person of John Dowse as an essential component of Wollaston's success. Making chemical manufacturing pay in early nineteenth century England was very hard work indeed.

Wollaston's work on organic chemicals also brings us back to his partnership with Tennant. According to the original revenue sharing agreement, proceeds from their joint ventures were to be shared equally. In February 1809, this agreement was renegotiated so as to increase Wollaston's share of the proceeds in recognition of his greater contributions. The new agreement, however, was never enacted for the organic chemical business, with the result that Tennant continued to receive half its proceeds until his death in 1815 . Even in this sphere of operation, where Tennant seems to have taken a more active role than in the platinum business, Usselman's analysis reveals "the fact that Wollaston did far more than 50 percent of the work" (p. 200). Despite difficulties and frustrations, Wollaston nevertheless persisted with organic chemistry while Tennant lived, perhaps - as Usselman suggests - as an expression of loyalty to the man who had eased his transition "from miserable doctor to independent entrepreneur" (p. 203). If true, this indicates that the reserved Wollaston understood one of the paramount rules of good business practice: people matter.

Wollaston's work in the field of organic chemistry also illustrates one final quality that can help us to understand this very private man's public successes. Wollaston, Usselman relates, kept the organic chemical business secret from his contemporaries. Thus, "it appeared to them that his published discoveries emanated ... from short-term bursts of 
inspiration" rather than from the intensive labor he and Dowse had performed in order to produce commercial chemical goods (p. 220). Wollaston, in turn, saw no reason to disabuse them. Wollaston's reserve is legendary, yet Usselman reveals him to have possessed surprising worldliness and social acumen. In doing so, he provides an instructive corrective to the widely accepted view of this complex character. Usselman shows that Wollaston certainly selected his friends with care, and that he was frequently rather secretive, but he also reveals Wollaston to have been far from reclusive and asocial.

This leads me to one final subject upon which Pure Intelligence is rather coy: Wollaston's private life. That Wollaston never married is a matter of record, but there is no suggestion in Usselman's biography of an intimate relationship of any kind. Wollaston is clearly characterized as a family man, who was generous to his sisters and enjoyed the companionship of family groups. In later life, he became friendly with a small number of much younger women, including Julia Hankey, but Usselman denies the possibility of any romantic entanglement. It is, of course, quite possible that insufficient documentary sources survive to allow a reliable analysis of Wollaston's intimate life. It is also possible that this is a deliberate exclusion. In my opinion, however, it would be preferable to make this decision explicit rather than simply to omit all discussion of this most human aspect of life.

\section{Conclusions}

Usselman's approach will not suit everyone. His focus on the technicalities of Wollaston's science, for example, may perhaps limit the book's readership. This would, in my view, be unfortunate since Pure Intelligence also demonstrates clearly that it is possible for a scientific biography to illuminate much more than its particular, individual subject. ${ }^{6}$ The lived life in science - as Wollaston's life so richly exemplifies - integrates the practice and outcome of science with circumstances that are far from merely personal. Professional, institutional, and even national contexts were all essential in shaping the direction of Wollaston's career. In understanding the course of that career, therefore, we learn about

${ }^{6} \mathrm{Cf}$. Myles Jackson's decision to eschew a purely biographical approach in his study of Fraunhofer. 


\section{DRAFT}

immensely more than the individual and this, it seems to me, is where the real power of scientific biography lies.

Usselman's biography persuaded me - and much more thoroughly than I expected - that Wollaston the scientist was very definitely "worth knowing" (p. 359). I am fascinated not merely by Usselman's portrayal of Wollaston as a man of his times but as an important figure in changing the world of professional science, by the very nature of the life he lived as much as by the work he did. I have indicated above that Pure Intelligence leaves me wanting to know more on a number of points. This should not, however, be interpreted as critical of Usselman's accomplishment. On the contrary, it seems to me the hallmark of outstanding scholarship that it opens avenues previously unseen, thereby expanding our field of interest. In Pure Intelligence we have a landmark study of what it meant to be a professional scientist in early $19^{\text {th }}$ century London, one I hope others will find as inspiring as I do.

\section{Bibliography}

Golinski, Jan. 1999. Science as Public Culture: Chemistry and Enlightenment in Britain, 17601820. Cambridge: Cambridge University Press.

Gooding, David. 1985. “'In Nature's School': Faraday as an Experimentalist.” In Gooding, David and Frank A. J. L. eds. Faraday Rediscovered: Essays on the Life and Work of Michael Faraday, 1791-1867. London: Macmillan, pp.105-132.

Hankins, Thomas L. 1979. "In Defence of Biography: The Use of Biography in the History of Science." History of Science, 17: 1-16.

Jackson, Myles W. 2000. Spectrum of Belief: Joseph von Fraunhofer and the Craft of Precision Optics. Cambridge, MA: MIT Press.

Jardine, Lisa. 2003. The Curious Life of Robert Hooke: The Man who Measured London. London: Harper Collins. 


\section{DRAFT}

Nye, Mary Jo. 2006. “Scientific Biography: History of Science by Another Means?” Isis, 97: 322-329.

Shapin, Steven. 1989. “Who was Robert Hooke?” In Robert Hooke: New Studies, ed. M. Hunter and S. Schaffer. Woodbridge, Suffolk: The Boydell Press, pp. 253-285. 